\title{
Towards Interoperability of Smart City Data Platforms
}

\author{
Matthias Buchinger \\ fortiss $\mathrm{GmbH}$ \\ buchinger@fortiss.org
}

\author{
Peter Kuhn \\ fortiss $\mathrm{GmbH}$ \\ pkuhn@fortiss.org
}

\author{
Anastasios Kalogeropoulos \\ fortiss $\mathrm{GmbH}$ \\ kalogeropoulos@fortiss.org
}

\author{
Dian Balta \\ fortiss $\mathrm{GmbH}$ \\ balta@fortiss.org
}

\begin{abstract}
We present a comprehensive analysis of the literature on interoperability of smart city data platforms in an attempt to conceptualize interoperability approaches. To this end, we propose a taxonomy of said approaches based on four dimensions with three characteristics each. The taxonomy can be used to classify interoperability approaches. We discuss implications for theory and practice and conclude with a first assessment of individual approaches towards their prospect of success.
\end{abstract}

\section{Introduction}

The concept of Smart Cities (SC)s is central to the future improvement of quality of life in metropolitan areas [22]. SC can be defined as an urban development vision of integrating and connecting multiple ICT solutions and city's assets in platforms enabling governments, businesses and citizens to communicate and work together using data from heterogeneous sources with the aim to improve the quality of life and enhance efficiency and economical value [1,9].

To enable this improvement, the concept relies on collecting and processing large amounts of data [21]. IT is considered pivotal to many infrastructural, ecological and economic challenges posed by the increasing urbanization $[9,41]$. Data platforms play an important role, as they support data management and application development [42]. This is also shown by a recent survey: $80 \%$ of German cities see a need for action on data platforms and $97 \%$ consider digitization as their "core business", but $88 \%$ also claim that they depend on external support in concrete projects [24].

A major challenge to a successful implementation of SCs is the supply of their data platforms with comprehensive and consistent data. [26]. As the data often originates from heterogeneous sources, therefore compatibility of a variety of different data sources and platforms is necessary [10]. However, current SC platforms have either limited functionality or are closed systems that are designed for a specific task and cannot be combined or extended [1]. This leads to fragmented silo solutions [27], a limitation on data exchange, and data accessibility for SC applications. The large number of different proprietary protocols and cloud services for SC applications (cf. e.g. [42]) further complicates the choice of the right platform [1]. Experience in other areas of public administration shows: in community-led projects, as it is also usual in SC (cf. e.g. [6]), often no supra-regional standards are defined [4], but rather individual solutions developed. This also turned out to be true for SC data platforms as literature shows (cf. e.g. [5]). Hence, standards alone will not enable more interoperability between SC data platforms in the coming years [28], as no consolidation of existing (pseudo) standards is expected [39].

Therefore, interoperability is a crucial feature of the underlying data platforms, as only linking the data from a wide range of different open and closed sources can lead to a valid, comprehensive and consistent database that is suitable for the development of various applications [1, 26]. In addition, interoperable solutions can prevent vendor lock-ins and help to cut costs for services, because they enable reusability of solutions and applications in different cities [8, 39, 40]. Thereby, it is also relevant to create open markets for third party services based on existing data [8].

While research has been conducted on interoperability, literature is lacking a comprehensive conceptualization of interoperability between SC data platforms. However, this would help better understand and assess interoperability approaches currently considered in research and practice. In order to improve this understanding and in an attempt to approach a comprehensive conceptualization, our paper will answer the following research question:

What are SC interoperability approaches and how can they be conceptualized towards a better understanding of data platform interoperability?

To answer this question, we conduct an extensive literature review and find six main topics of focuses. Based on this and seven expert interviews, we develop four dimensions of interoperability approaches with three characteristics each. We discuss the results and conclude with limitations and future research. The findings of this paper can help to identify future research directions and provides guidelines for decision-makers to realize successful data platforms. 


\section{Theoretical Background}

In this chapter, we give an overview over three key concepts, which are central to our research topic: SC as the application domain, data platforms as a central component of SCs, and interoperability as we focus on the communication between such platforms.

\subsection{Smart City}

SC is a highly discussed topic in scientific literature aiming to connect governments, businesses, and citizens using technologies like IoT, Big Data, Cloud Computing, and Geomatics, enabling the usage of a host of data from heterogeneous sources and intending to create a sustainable environment, improve the quality of life, as well as enhance efficiency and economical value $[1,9,10]$.

Thereby, SC literature concentrates on three main topics. The first topic are approaches to and the relevance of open standards and data platforms for the development and deployment of SC applications (e.g. $[1,26,42])$. The second topic are theoretical models that are intended to support the selection and development of suitable SC applications (e.g. [13, 17]), for example through a criteria-based evaluating framework [17]. A third topic is the implementation and analysis of prototypical SC applications, with a focus on energy (e.g. $[1,26,35])$, mobility (e.g. [1, 26, 35]) and administration (e.g. [35]), but also many other fields of action (cf. e.g. [6]). A comprehensive list of projects and initiatives in Germany as well as an analysis of important fields of action is presented in from bitkom [6], while van der Klaauw [42] compares the most relevant IoT platforms for SC projects.

\subsection{Data Platform}

Data platforms are a central component of SC solutions. They support data flow management and application development [42] and enable government, businesses and citizens to communicate and work together using an enormous amount of diverse data of different types and from heterogeneous sources [9].

In literature, SC data platforms are mostly characterized as big data platforms (cf. e.g. $[12,26]$ ) and/or IoT platforms (cf. e.g. [42]) [10]. Both characterizations can apply, since SC has - on the on hand - many overlaps with IoT technologies like the usage of information and communication technology for the connection of diverse physical objects like sensors and the internet [1]. On the other hand, as described in chapter 1 , big amounts of different data are gathered, combined, and computed, which are the defining characteristic of a big data platform [21].
Further, the platform must be able to "deal with both historical data and real-time data [as well as] being flexible to handle different scales/types of data" [12].

\subsection{Interoperability}

There exist several different definitions of the term interoperability in scientific literature (cf. e.g. [32]). The International Organization for Standardization (ISO) [25] defines interoperability generically and with a focus on the exchange of information between units as the "capability to communicate, execute programs, or transfer data among various functional units in a manner that requires the user to have little or no knowledge of the unique characteristics of those". In its definition of interoperability for the eGovernment sector, the European Commission [15] includes not only the concept of data exchange, but also the sharing of common knowledge and underlines the importance of harmonized business processes. Maheshwari and Janssen [32] define the term interoperability as: "the ability of entities to work together covering aspects ranging from the technical to the organizational level." Combining these three definitions, interoperability is the ability of disparate and diverse system components, ICT systems, or organizations to communicate, transfer information/knowledge, execute programs, and work together, covering aspects ranging from the technical to the organizational level, to achieve mutually beneficial and agreed common goals [15, 25, 32].

In a SC framework, Brutti et al. [8] differentiate horizontal and a vertical interoperability (Figure 1). Horizontal interoperability considers interoperability between data platforms, while vertical interoperability addresses the interoperability between platform and data user as well as data source. Bröring et al. [7] use this distinction, too, to discuss IoT systems. Although mainly focusing on vertical interoperability, they emphasis on horizontal interoperability as equally important for the successful usage of IoT ecosystems, also not yet established.



Figure 1: The two dimensions of interoperability Source: Own depicition

\section{Research approach}

The general research approach of this paper is following the design science research by Hevner et al. 
2004. We chose this approach to allow an iterative development of the research artefact and the consideration of both existing theory and knowledge from practice. For this purpose, we followed the methodology as described by Peffers et al. [36]. It is a guideline for building and evaluating IT artifacts often used in information system research, and is also recommended form Nickerson et al. for the development of a taxonomy [34]. We followed the methodology by identifying the problem constituting the motivation for the research and defining the objective for a solution. The collection of information and the design and development of the artefact was done in iterations applying the taxonomy development method described by Nickerson et al. [34]. Therefor we conducted an extensive literature review after Petersen et al. [37] and semi-structured guided expert interviews following Gläser and Laudel [20].

\subsection{Literature review}

We conducted an extensive literature review to get a comprehensive overview of the topic SC data platforms following Petersen et al. [37]. As reference, we used the work from Faber et al. [16], which presented a study about business ecosystem types in literature also using the method by Petersen et al. [37]. We used this method, as it helps to efficiently structure the published research results for a certain topic [37].

As research question motivating the literature review we defined based on the general question addressed by this work: What different types of SC interoperability approaches are presented in literature?

For the selection of the main sources and databases relevant for that topic, similar to Faber et al. [16] we identified as relevant research areas e-governance, computer science, and information systems. These were chosen since SC is once a topic in e-governance [3] and second, together with data platforms and interoperability also a topic in computer science and information systems.

As resource for the literature review, we searched electronic databases. As most relevant databases, we selected Scopus, Association for Computing Machinery (ACM), Electrical and Electronics Engineers (IEEE), ScienceDirect, SpringerLink and Web of Science, as all six cover publications of the previously identified research areas.

We conducted the search in two iterations. At first, we searched Scopus using broad search queries to get a better overview of the existing literature related to the different domains of interest interoperability, SC, and data platform (see Table 1). Since Scopus as more generalized scientific database includes a high amount of various journals and conference publications in diverse research areas, we further specified the relevant conferences and journals for the above mentioned research areas. In total, we included 30 sources listed in Table 2. In these sources, we searched for each of the three domains of interest independently in abstract, title and keywords and then also combining them. Furthermore, we included standardization as a related term of interoperability. The used queries and the amount of results are listed in Table 1.

Table 1: Search key words and amount of results for Scopus database

\begin{tabular}{|l|r|}
\hline \multicolumn{1}{|c|}{ Search key words } & $\begin{array}{c}\text { Search in } \\
\text { abstract, title, } \\
\text { keywords }\end{array}$ \\
\hline "interoperability" & 855 \\
\hline "smart city" & 252 \\
\hline "data platform" & 81 \\
\hline "data platform" AND "standardization" & 2 \\
\hline "smart city" AND "standardization" & 11 \\
\hline "data platform" AND "interoperability" & 10 \\
\hline "smart city" AND "interoperability" & 36 \\
\hline "smart city" AND "data platform" & 11 \\
\hline "smart city" AND "data platform" AND & 1 \\
"standardization" & 3 \\
\hline "smart city" AND "data platform" AND & 1262 \\
\hline "interoperability" & 1134 \\
\hline sum & \\
\hline Duplicates eliminated & \\
\hline
\end{tabular}

We found the most results for the term "interoperability" (855), while "smart city" (252) as well as "data platform" (81) had significantly lower numbers. Combining two of the terms caused already a heavy decrease of results, while combining "smart city" and "data platform" and "standardization" had only one. Combining "smart city" and "data platform" and "interoperability" resulted in three papers.

In total, after eliminating duplications, the systemic search of databases with our search queries resulted in 1134 potentially relevant papers. Due to this high amount, we read and evaluated the titles to sort out papers with no clear focus on at least one of the key words ending up with 493 papers distributed among 24 journals and conferences as shown in Table 2. Thereby most remaining papers were published in HICSS conference proceedings. Following the approach presented by Petersen et al. [37] and Faber et al. [16], we further screened and evaluated the keywords of the papers and in a second step also the abstracts. Selection criterion was always a clearly recognizable reference to at least two of the three main topics. From the remaining 21 paper, we got access to 13 , since the others were not freely available through the channels of our institution. We read and evaluated the full text of all remaining 13 papers and excluded papers without clear input on the interoperability of SC data platforms. This leaded in the end to nine papers with clear focus on this topic. 
Table 2: Search and screening of Scopus database

\begin{tabular}{|c|c|c|c|c|c|c|}
\hline \multicolumn{2}{|l|}{ Journals and Conferences } & \multicolumn{5}{|c|}{ Search and Screening phases } \\
\hline Source & Type & $\begin{array}{c}\text { Evaluate } \\
\text { title }\end{array}$ & $\begin{array}{l}\text { Evaluate } \\
\text { title and } \\
\text { key- } \\
\text { words }\end{array}$ & $\begin{array}{l}\text { Evaluate } \\
\text { abstract }\end{array}$ & $\begin{array}{c}\text { Available } \\
\text { fulltext }\end{array}$ & $\begin{array}{l}\text { Evaluate } \\
\text { fulltext }\end{array}$ \\
\hline Academy of Management & Conference & & & & & \\
\hline SIGMOD & Conference & 19 & 3 & & & \\
\hline Communications of the $\mathrm{ACM}$ & Journal & 24 & 4 & & & \\
\hline ECIS & Conference & & & & & \\
\hline EJIS & Journal & 5 & 1 & & & \\
\hline $\begin{array}{l}\text { Electronic Government, an } \\
\text { International Journal }\end{array}$ & Journal & 18 & 5 & 1 & & \\
\hline Government Information Quarterly & Journal & 45 & 16 & 6 & 2 & 2 \\
\hline IJEGR & Journal & 22 & 4 & & & \\
\hline Information Polity & Journal & 25 & 4 & & & \\
\hline Information Systems Journal & Journal & 2 & 1 & 1 & & \\
\hline Information Systems Research & Journal & 1 & 1 & & & \\
\hline $\begin{array}{l}\text { Information Technology and } \\
\text { Management }\end{array}$ & Journal & 3 & & & & \\
\hline $\begin{array}{l}\text { International Journal of Electronic } \\
\text { Governance }\end{array}$ & Journal & 12 & 3 & 1 & & \\
\hline $\begin{array}{l}\text { International Journal of Public } \\
\text { Administration }\end{array}$ & Journal & 3 & 3 & 1 & 1 & 1 \\
\hline IRMA & Conference & & & & & \\
\hline JEIM & Journal & 6 & & & & \\
\hline Journal of AIS & Journal & 1 & & & & \\
\hline Journal of Information Technology & Journal & 4 & & & & \\
\hline $\begin{array}{l}\text { Journal of Management } \\
\text { Information Systems }\end{array}$ & Journal & 7 & 5 & 1 & 1 & 1 \\
\hline $\begin{array}{l}\text { Journal of Strategic Information } \\
\text { Systems }\end{array}$ & Journal & 2 & & & & \\
\hline $\begin{array}{l}\text { Journal Public Administration } \\
\text { Research Theory }\end{array}$ & Journal & & & & & \\
\hline MISQ & Journal & 5 & 1 & & & \\
\hline PACIS & Conference & & & & & \\
\hline Public Administration Review & Journal & 2 & 1 & & & \\
\hline $\begin{array}{l}\text { Public Performance Management } \\
\text { Review }\end{array}$ & Journal & & & & & \\
\hline Social Science Computer Review & Journal & 18 & 6 & 1 & 1 & \\
\hline $\begin{array}{l}\text { Journal of Information Technology } \\
\text { and Politics }\end{array}$ & Journal & 1 & & & & \\
\hline ECEG & Conference & 99 & 25 & 4 & 3 & 2 \\
\hline HICSS & Conference & 114 & 22 & 5 & 5 & 3 \\
\hline Information Systems Journal & Journal & 1 & & & & \\
\hline Total & & 439 & 105 & 21 & 13 & 9 \\
\hline
\end{tabular}

In a second iteration, we extended the literature review with the databases ACM, IEEE, ScienceDirect, SpringerLink and Web of Science. To that end, we used the query: "smart city" AND "data platform" OR "smart city" AND "interoperability" OR "smart city" AND "standardization" OR "data platform" AND "interoperability" OR "data platform" AND "standardization". Thereby we used the same keywords as in Scopus, but because we already got an overview about the relevance of the single key words, just without splitting the search and only using twoword combinations to already limit the results to more relevant papers. Because SpringerLink provides no possibility to search with a specific query only in title, abstract, and keywords and since searching in general (including full texts) leaded to 18.501 results with no possibility of automatized filter, SpringerLink was excluded. The further results are shown in Table 3.

Searching in abstract, title, and keywords with the defined query resulted in 574 papers for all sources whereby in ScienceDirect with 207 the most while in ACM with 35 the least relevant paper were found. We further followed the same approach as described above for the results from Scopus, however, the evaluation of title and keywords was done in one-step due to the smaller amount of results. After eliminating duplications, from the 503 results 19 were evaluated as most relevant for our research question. Of those 19 nine were from IEEE one remain from ScienceDirect.

Table 3: Search and screening of ASM, IEEE, ScienceDirect, and WebofScience

\begin{tabular}{|l|c|c|c|c|c|c|}
\multicolumn{1}{c|}{$\begin{array}{c}\text { Phase } \\
\text { Source }\end{array}$} & $\begin{array}{c}\text { Search in } \\
\text { abstract, } \\
\text { title, } \\
\text { keywords }\end{array}$ & $\begin{array}{c}\text { Duplicates } \\
\text { eliminated }\end{array}$ & $\begin{array}{c}\text { Evaluate } \\
\text { title and } \\
\text { keywords }\end{array}$ & $\begin{array}{c}\text { Evaluate } \\
\text { abstract }\end{array}$ & $\begin{array}{c}\text { Available } \\
\text { fulltext }\end{array}$ & $\begin{array}{c}\text { Evaluate } \\
\text { fulltext }\end{array}$ \\
\hline ACM & 35 & 35 & 14 & 9 & 9 & 4 \\
\hline IEEE & 166 & 162 & 40 & 25 & 25 & 9 \\
\hline ScienceDirect & 207 & 203 & 7 & 4 & 1 & 1 \\
\hline WebofScience & 166 & 103 & 19 & 10 & 8 & 5 \\
\hline \multicolumn{1}{r|}{ Total } & $\mathbf{5 7 4}$ & $\mathbf{5 0 3}$ & $\mathbf{8 0}$ & $\mathbf{4 8}$ & $\mathbf{4 3}$ & $\mathbf{1 9}$ \\
\hline
\end{tabular}

\subsection{Expert Interviews}

In addition to the literature review, we conducted six semi-structured guided expert interviews based on Gläser and Laudel [20]. The seven interviewed experts were from four different cities as shown in Table 4 (Code: C1.., C2..; C3.., C4.). The experts were chosen for their expertise in organizational and technical aspects of SC data platforms.

Table 4: Interviewed experts

\begin{tabular}{|l|l|l|}
\hline Code & Role & Focus \\
\hline C1D1 & City department for digitalisation & Organizational \& technical \\
\hline C1D2 & City department for digitalisation & Technical \\
\hline C2D1 & City department for digitalisation & Organizational \\
\hline C3P1 & City organisation for SM projects & Organizational \\
\hline C3P2 & City organisation for SM projects & Technical \\
\hline C4GuS & City department for geoinformatics \& surveying & Technical \\
\hline C4U & University SM projects & Organizational \\
\hline
\end{tabular}

Three interview partners work in leading/strategy positions in a city's department for digitalization, responsible for or included in the development of SC (C1D1, C1D2, C2D1). Two interviewees were employees from a city owned company responsible for further developing a comprehensive SC concept (C3P1, C3P2). Moreover, one interviewee was from the city department for geoinformatics and surveying with leading position in SC development $(\mathrm{C} 4 \mathrm{GuS})$ and one was an employee in a university working in SC projects $(\mathrm{C} 4 \mathrm{U})$.

In general, the interviews were structured in four sections. The first part contained basic questions, in the second section, we asked about the actual projects they were included in and the therein deployed SC data platforms. The third section included question regarding important aspects for interoperability and its relevance for SC projects while the last section were open questions about remaining challenges regarding interoperability of SC data platforms.

All interviewees got the questions and additional information about our research goal a few days before the interview. In case of questions before the actual interview, these were clarified via mail or a call. The 
interviews were held one-on-one, only in one case two experts were interviewed together as requested by them. The interviews took place between June and July 2020 and lasted between 23 and 52 minutes. After asking the interviewees for permission, all interviews were recorded for the later analysis. During the interviews, the relevant statements for the research question were noted. Through two iterations of listening of the recording, these notes were completed. Thereby especially all descriptions of relevant dimensions and possible approaches were noted.

\subsection{Taxonomy building}

The information gathered in the literature review and the interviews were used to develop a taxonomy following the method described by Nickerson et al. [34]. Following the authors, a taxonomy, often also used interchangeably to classification scheme, is a system of groupings that are derived conceptually or empirically [34]. The application of the method by Weking et al. [43] was used as a reference.

The development of the taxonomy was an iterative approach. Beginning with the development of a metacharacteristic, which "serve as the basis for the choice of characteristics in the taxonomy" [34] and the definition of ending conditions we chose the components organizational and technical as metacharacteristic, which are described as basic factors for interoperability by Maheshwari and Janssen [32]. Ending conditions were not defined, since we had a given amount of input for the development of the method. As a consequence, the results cannot be considered as concluding collection of relevant dimensions. In our estimation, however, it is yet not possible to draw up a conclusive list of relevant dimensions regarding interoperability of SC data platforms, caused by the early stage of development.

Starting from the meta-characteristic we conducted three iterations of method development. Since our research design is based on analytical-deductive methods focusing on the analysis and interpretation of qualitative empirical data (cf. [33]), in all iterations an empirical to conceptual approach was used to identify and group common characteristics into dimensions to create or reverse the taxonomy (cf. [34]).

In the first iteration, we analyzed characteristics of SC data platform interoperability discussed in the nine paper from Scopus and derived three main domains with different approaches: degree of data openness, role of the city, and quality of exchanged data.

In the second iteration we analysed the 19 paper selected from the four other scientific data basis and revised the initial taxonomy. As a result, we renamed the domain quality of exchanged data to level of data interoperability. Furthermore, we included the dimension architecture pattern and added further characteristics to the existing dimensions.

In a third iteration, we analysed the interviews and included the contained input in the taxonomy, whereby gaps in the existing domains were closed but no new ones were added, although also new aspects highly relevant for the interoperability of SC data platforms were mentioned. The reason for that is that these aspects were not far enough developed of discussed neither in the interviews nor in the literature analysed, to derive new dimensions from them. However, these aspects are mentioned in chapter 5 as relevant points for further research.

\section{Findings}

In this chapter, we present the findings from the literature review and the interviews. In the first section the general results of the literature review are analyzed and in the second section the therefrom and from the interviews derived dimensions of interoperability.

\subsection{Results from the literature review}

The first result of this paper is a comprehensive literature analyses of relevant papers from the five databases ACM, IEEE, ScienceDirect, Scopus, and WebofScience. After selecting the 28 most relevant papers, we analyzed the topics they focus on to find approaches to interoperability of data platforms.

Based on our analysis, the focus topics of the relevant literature can be structured using the in the following described six categories (see Table 5).

Table 5: Main categories from the analyzed papers

\begin{tabular}{|c|c|c|c|c|c|c|}
\hline & $\begin{array}{c}\text { Architecture } \\
\text { principles }\end{array}$ & Case study & $\begin{array}{l}\text { Comparison } \\
\text { of platforms }\end{array}$ & $\begin{array}{c}\text { Platform / } \\
\text { service } \\
\text { (architecture) } \\
\text { dev. }\end{array}$ & $\begin{array}{l}\text { Evaluation } \\
\text { framework }\end{array}$ & Basic work \\
\hline Bhatt et al. 2017 [5] & $x$ & & & & & \\
\hline Brutti et al. 2018 [8] & $x$ & & & & & \\
\hline Cohen, Money 2017 [13] & $\mathrm{x}$ & & & & & \\
\hline Brutti et al. $2019[9]$ & $x$ & & & $x$ & & \\
\hline Zarko et al. 2019 [45] & $x$ & & & $x$ & & \\
\hline Wirzet al. 2020 [44] & $x$ & $x$ & & & & $x$ \\
\hline Lopes et al. $2016[30]$ & & $x$ & & $x$ & & \\
\hline Danneels et al. 2017 [14] & & $\mathrm{x}$ & & & $x$ & \\
\hline Maheshwari, Janssen 2014 [32] & & $x$ & & & & $x$ \\
\hline Sotres et al. 2019 [39] & & $x$ & & & & \\
\hline Soe 2017 [38] & & $x$ & & & & \\
\hline Hernández et al. 2020 [22] & & $x$ & & & & \\
\hline Fahmideh, Zowghi 2018 [17] & & & $x$ & & $x$ & \\
\hline Fahmideh, Zowghi 2020 [18] & & & $x$ & & & \\
\hline Chaturvedi, Kolbe 2018 [10] & & & & $x$ & & \\
\hline Ferguson et al. 2016 [19] & & & & $x$ & & \\
\hline Loutas et al. 2014 [31] & & & & $x$ & & \\
\hline Tolcha et al. $2018[40]$ & & & & $x$ & & \\
\hline Kolbe et al. 2017 [28] & & & & $x$ & & \\
\hline An et al. 2019 [2] & & & & $x$ & & \\
\hline Valja, Ladhe 2015 [41] & & & & $x$ & & \\
\hline Kazmi et al. 2018 [27] & & & & $x$ & & \\
\hline Chaturvedi, Kolbe 2019[11] & & & & $x$ & & \\
\hline Hwang et al. $2019[23]$ & & & & & $x$ & \\
\hline Zhao, Xia 2014 [46] & & & & & & $\mathrm{x}$ \\
\hline Ojo et al. 2015 [35] & & & & & & $\mathrm{x}$ \\
\hline Anthopoulos, Fitsilis 2013 [3] & & & & & & $x$ \\
\hline Lewis 2012 [29] & & & & & & $x$ \\
\hline
\end{tabular}


From the 28 relevant papers, six present architecture principles. They focus on aspects such as interoperability through standardized interfaces [5] or open specifications [8], defining technical requirements to establish a SC projects [13], and to break down silo barriers between SC indicatives [9]. Furthermore, Zarko et al. [45] presents the general concept of interoperability through a middleware solution and Wirtz et al. [44] describe basic technological services needed for SCs.

Seven of the relevant papers focus on case studies. Among others Wirtz et al. [44], Lopes et al. [30], and Soe [38], describe approaches for interoperability in $\mathrm{SC}$ projects of different cities focusing different views.

Two papers present a comparison of different platforms. One presents an extensive comparison of nine platforms [17], the other a comparison of development approaches for SC data platforms [18].

Eleven papers develop architectures and prototypes of data platforms or of related services. Data platforms are developed e.g. from Ferguson et al. [19] (cloud-based linked data platform for SC) and Kazmi et al. [27] (platform providing access to data and services from any source). Tolcha et al. [40] (central data hub to capture SC data in independently distributed repositories) and An et al. [2] (interworking solution for two global SC platforms) present middleware solutions for interoperability between SC data platforms. Interface solutions were among others presented from Chaturvedi and Kolbe [11].

Moreover, Danneels et al. [14], Hwang et al. [23], and Fahmideh and Zowghi [17] introduce evaluation frameworks for SC data platforms, for example presenting 34 questions to evaluate the suitability of SC platforms' architectures by analysing architectural characteristics and their fit to the requirements [17].

Six papers were classified as basic work, since they cover theoretical aspects relevant for interoperability of SC data platforms not specifically restricted to one of the other categories, like Zhoa and Xia [46] (interorganizational standards) and Ojo et al. [35] (emerging convergence of SCs and open data initiatives).

In total, the analyses of the 28 paper showed, that lot of different topics in SC literature exist. Although interoperability and interoperability standards for SC data platforms are also a subject of attention (cf. e.g. $[11,38,46])$, no standard approach have been accepted by a broad mass, making interoperability between different solutions again not easy [28]. The analyses also showed, that multiple approaches to improve the interoperability in SCs exist. Since these can differ in diverse ways, we extracted, grouped, and structured the main factors for interoperability approaches from all analyzed papers as described in chapter 4.2.

\subsection{Dimensions of interoperability approaches}

Based on the literature review and additional seven expert interviews we identified four dimensions of interoperability approaches with three characteristics each. For the dimensions level of data interoperability, architectural pattern, role of the city, and degree of data openness, the respective characteristics represent manifestations, currently discussed in literature and praxis. They are depict in Figure 2 and described in the following.

\begin{tabular}{|l|c|c|c|}
\hline Dimension & \multicolumn{3}{|c|}{ Characteristics } \\
\hline $\begin{array}{l}\text { Level of data } \\
\text { interoperability }\end{array}$ & $\begin{array}{c}\text { Semantic } \\
\text { interoperability }\end{array}$ & $\begin{array}{c}\text { Structural } \\
\text { interoperability }\end{array}$ & $\begin{array}{c}\text { Foundational } \\
\text { interoperability }\end{array}$ \\
\hline $\begin{array}{l}\text { Architecture } \\
\text { pattern }\end{array}$ & $\begin{array}{c}\text { Interoperability via } \\
\text { central data platform }\end{array}$ & $\begin{array}{c}\text { Interoperability via } \\
\text { middleware }\end{array}$ & $\begin{array}{c}\text { Interoperability via } \\
\text { APIs }\end{array}$ \\
\hline Role of the city & Autopoietic & Connectionistic & Cognitivistic \\
\hline $\begin{array}{l}\text { Degree of data } \\
\text { openness }\end{array}$ & Open data & Licensing models & Data marketplace \\
\hline \multicolumn{2}{|c|}{ Promising approaches } \\
\hline
\end{tabular}

Figure 2: The four dimensions and their characteristics Source: Own depicition

The first dimension is the level of data interoperability. Data is at the core of SCs and must be gathered from diverse sources to establish a comprehensive and consistent database as described in chapter 1 . The quality of the data regarding its further processability is thereby influenced by the level of interoperability between platforms (and sensors) [39]. Overall, several levels of interoperability exists (cf. e.g. [28]), but mainly three are discussed regarding SC data platforms (cf. e.g. [22, 39]): foundational, structural, and semantic interoperability. Foundational interoperability allows systems to exchange data [29] gathered with different communication protocols by using gateways, but without the capability to interpret the data [22, 39]. Structural interoperability allows to exchange meaningful data [29], as the structure, format, and syntax of the data is defined [22] through the usage of shared languages or protocols like JSON or MQTT [39]. Though, the proposed middleware specifications can remain unclear when they belong to different contexts, thus interoperability remains a problem [39]. Semantic interoperability means that systems understand the precise meaning of exchanged information due to common data models [22, 29, 39]. The three approaches build up on each other with semantic interoperability including the others [29].

The second dimension is the architecture pattern. Following Hwang et al. [23] we distinguish three patterns repeatedly found in the analysed papers and interviews: interoperability via a central data platform, interoperability via middleware, and interoperability via APIs. They differ in, whether same API standards 
are needed in general and where the data is stored [23]. A concept for interoperability of different data platforms via APIs is e.g. discussed by Ferguson et al. [19]. Bhatt et al. [5] describe in their work a concept called pivotal points of interoperability, which provides common architecture principles for SC systems, so only at specific common points standardized interfaces need to be used to make these systems interoperable. However, in both cases, platforms (and services) have to use the same API standards (at least in the pivotal points) to gain access or exchange data with the other data platforms [23]. On the contrary, for interoperability via specific middleware the data platforms do not need to use the same standards, since a middleware is used to convert the data representation of the source platform to another's platform needs [23]. This approach is used among others from Chaturvedi et al. [11], Lopes et al. [30], and Zarko et al. [45]. The middleware serves as a search and mediation layer between databases (and applications) [45]. Thereby, applications can access data form different data sources, so that no central SC data platform is needed, but still a central data access is possible (cf. e.g. Interv. C1D1). However, all standards used from the different sources (data platforms) still must be supported by the middleware. The third approach in this dimension is interoperability via a central data platform, which is discussed among others by Cohen et al. [13], Soe [38], and Tolcha et al. [40]. The basic concept is, that a "federation layer is created on top of cities' IoT platforms" [23]. Since a middleware can be used to connect different data platforms and restore their data centrally, the demarcation between interoperability via specific middleware and via a central data platform is not always clear. We make the distinction based on the fact that a middleware allows applications to access different sources of SC data while in the other case all $\mathrm{SC}$ data is re-stored on one platform.

The third dimension is about the role of the city regarding the provision of the SC data platform. The findings of our analyses, especially from the interviews, reflect the results of Danneels et al. [14], which defined three types of open government data platforms based on how much influence and action the government, in our case the city, takes in the management and control of the data platform. One approach is the cognitivistic one, where the city opens its data for re-use without intervene much. The second approach is connectionistic, where the city acts as a central coordination mechanism and creates communities around the data, comparable to an ecosystem like amazon (Interv. C4GuS) or the Apple Appstore (Interv. C4U). However, thereby all the power, responsibility as well as the operating of the data infrastructure remains in city organs. In the third approach, the autopoietic one, the city ensure that the open data ecosystem organizes itself rather than actively coordinating the actors in it. Therefore, the city remains a central party in the ecosystem but also delegates' responsibilities also to external parties.

The fourth dimension is the degree of data openness, which is in particular interconnected with the third dimension, as the role of the city is decisive for the extent to which the city can determine the use of the data. The degree of data openness is mentioned in different analysed papers like Hernández et al. [22] and Ojo et al. [35], but only Välja and Ladhe [41] consider it more in detail. In general, the main questions are, who can inject and enrich data in a platform and how is the access regulated [14]. We extracted three approaches regarding this dimension from the literature and the conducted interviews. One approach is to make the data, to a legally acceptable extent, open to the public. Thereby companies and private persons can use the data to build (commercial) applications on it, without having to pay for the usage of the data or the platform and without specific restrictions. This approach was explained in more interviews (Interv. C2D1, Interv. C4GuS) as most probable, especially in the beginning, since the city wants to incentivize external parties to build SC applications based on the existing (mostly not yet fully consistency) data. Another approach foreseen from interviewed experts is a licensing model for access to the data (Interv. C1D1). A license can be a contract concluded individually with one external party or a general contract, which everybody who wants to access the data must accept. Thereby, certain regulations for the data usage can be ensured through the city. Optionally also a fee for the data access can be charged (e.g. pay per month for platform access, pay per amount of used data). The third approach, a data marketplace, is discussed by Välja and Ladhe [41]. The marketplace is supposed to enable the exchange and sharing of data between the city and other organizations, which also can provide data (cf. e.g. Interv.C1D1, Interv.C3P1). The main advantage of a SC marketplace described in the paper and also mentioned in the interviews (cf. e.g. C1D1) is, that thereby companies can have a new business model by sharing their data relevant to the SC with the city and other organizations for payment. This would increase the incentive for companies to share their date and enrich the overall amount of data available. Further, a marketplace platform would close the "technological gap that especially small companies are facing, and will allow knowledge based business ventures to become reality, where public data is mixed with company data in a trustworthy way" [41]. 


\section{Discussion}

In this chapter, we discuss the result from chapter 4. We focus on advantages and disadvantages of the different approaches characterized in the four dimensions. Based on that, we narrow down promising approaches (see Figure 2). Following Maheshwari and Janssen [32], we discuss the dimensions from a technical and a organizational point of view.

For the first dimension, the level of data interoperability, semantic interoperability is arguably the most promising approach. From an organizational perspective, foundational interoperability is easier to implement. However, from a technical perspective, literature and experts are quite consistent, that a semantic interoperability is required in the SC context. Foundational and structural interoperability can enable collecting data from different sources to make all pieces of information available. But, they do not enable seamless service creation out of this data, since in a SC a huge amount of different information with different formats, meanings, and relations to different domains must be combined [39]. A foundational and also a structural interoperability cannot ensure the right interpretation of all these data [22, 39].

For the second dimension, the architectural pattern, interoperability via a central data platform or via a middleware should be favoured over interoperability via APIs. Architecture patterns strongly depend on the already existing infrastructure and the organizational structure of a city. Still, from a technical perspective as mentioned in chapter 4.2, interoperability via APIs is not a good strategy in the short term, since broadly acknowledged standards will not prevail in time [39]. The literature and especially the interviews showed, that the concepts of middleware and a central data platform are discussed more intensive (cf. e.g. Interv. C1D1, Interv. C4GuS). For the middleware, the main argument is that "in a distributed environment, where multiple stakeholders and sensor owners are involved with proprietary sensors, not all of them would be willing to inject their proprietary data into a third-party data storage" [11]. Furthermore, this approach prevents a huge amount of redundant data storage (Interv. C2D1). However, the mediation to the original decentral data sources via the middleware would cause an increase of requests to the individual platforms with an increasing amount of applications (Interv. C4GuS). These may not be designed for that much traffic. Also, their operators may not want to or not be able to provide the additional effort to support the increased data queries (Interv. C4GuS). Consequently, a centralised SC platform has a big advantage. The disadvantage would be as mentioned, the occurring redundancy of stored data, since in "large IoT system like in a SC, different organizations may already have deployed different platforms [and] replacing them by a single one is often unrealistic" [2].

For the third dimension (role of the city), our analyses showed that the cognitivist approach seems to be unsuitable for SC data platforms. First and foremost for privacy and security reasons. But also for the need to incentivize external organizations to use the SC data for the development of applications for the citizens this is the case. The city must be able to actively manage and control the data from the city (Interv. C1D2). An assessment of the other two approaches is less straight forward, since they are highly dependent on the SC ecosystem and the input of "external" data e.g. from companies. The interviews showed that right now the connectionistic approach is more common, particularly as mostly the cities advance SC projects and need to incentivize other developers and organizations to develop SC applications by building up and providing a functioning ecosystem which can be the bases for new business models (cf. e.g. Interv. C2D1). In a long-term perspective, though, the goal mentioned from the experts is to change to an autopoietic characterization where the ecosystem manages itself to a larger extent, providing external parties enough benefits to participating and providing data without getting incentivized, so the city is only in charge of enforcing some regulations (e.g. privacy regulations) (cf. e.g. $\mathrm{C} 3 \mathrm{P} 1$ ). However, the literature review showed that there is still research needed in this area, especially because also decision makers in SC project have still not found concrete answers regarding the best approach (Interv. C1D1, Interv. C2D1).

The different approaches of the fourth dimension, degree of data openness, also have an impact to the role of the city regarding the provision of the SC data platform. A licensing model with fees for example requires a higher service offering from the city, while a marketplace approach would also take more responsibility from companies for the operation of the platform. Although, we found no fully developed concepts it seems to be clear that it is an important function of SC data platforms to allow also external parties accessing the data. However, if and how they should pay for it is still a highly discussed topic in SC projects (cf. e.g. Interv. C1D1, Interv. C2D1), which should also be addressed by further research.

Over all, the taxonomy provides a structure for the discussion of different interoperability approaches and gives first conclusions on promising and less promising strategies. However, the discussion also shows the need for further research on some dimensions to narrow down the options for practice and improve the theoretical understanding. 


\section{Conclusion and Outlook}

In this paper, we present a comprehensive analysis of the literature on interoperability of SC data platforms and an attempt to conceptualize interoperability approaches. To this end, we propose a taxonomy of said approaches based on four dimensions with three characteristics each. We conclude with a first assessment of individual approaches towards their prospect of success.

The findings of this paper have limitations that restrain their general applicability and should be met with further research. Although our literature review was systematic and complemented by expert interviews, the presented dimensions are not necessarily conclusive. Other dimensions should be considered in future research. First directions for possible further dimensions are mentioned in the expert interviews. Especially ethical and legal topics (e.g. contractual frameworks) in regard to SC were mentioned (Interv. C1D1, C2D1, Inter. C3P2), and are only superficially considered in literature (cf. e.g. [31]). To identify all missing existing dimensions, the taxonomy has to be also further evaluated with examples from practice. Moreover, the current taxonomy allows only for a discussion and confrontation of interoperability approaches. Further work should aim at assessing the different approaches towards their prospect of success. For theory and practice would especially be interesting to investigate the relationship of certain characteristics with the interoperability of a data platform.

Although limitations exist, we believe that our research is valuable for theory and practice. The taxonomy can be used to discuss and confront interoperability approaches and shows that future research is needed in the different dimensions. Moreover, it can help decision makers to gain an overview over important decisions to take regarding interoperability of data platform interoperability as well as pros and cons of existing approaches.

\section{References}

[1] Ahlgren, B., M. Hidell, and E.C.-H. Ngai, "Internet of Things for Smart Cities: Interoperability and Open Data", IEEE Internet Computing, 20(6), 2016, pp. 52-56.

[2] An, J., F. Le Gall, J. Kim, J. Yun, J. Hwang, M. Bauer, M. Zhao, and J. Song, "Toward Global IoT-Enabled Smart Cities Interworking Using Adaptive Semantic Adapter", IEEE Internet Things Journal, 6(3), 2019, pp. 5753-5765.

[3] Anthopoulos, L. and P. Fitsilis, "Evolution Roadmaps for Smart Cities: Determining Viable Paths", in Proceedings of the 13th European Conference on eGovernment. 2013.
[4] Balta, D. and H. Krcmar, "Managing Standardization in eGovernment: A Coordination Theory based Analysis Framework", in Electronic Government. 2018.

[5] Bhatt, V., A. Brutti, M. Burns, and A. Frascella, "An Approach to Provide Shared Architectural Principles for Interoperable Smart Cities", in Computational Science and Its Applications - ICCSA 2017. 2017.

[6] bitkom, Smart-City-Atlas: Die kommunale digitale Transformation in Deutschland, 2019.

[7] Bröring, A., S. Schmid, C.-K. Schindhelm, A. Khelil, S. Kabisch, D. Kramer, D. Le Phuoc, J. Mitic, D. Anicic, and E. Teniente, "Enabling IoT Ecosystems through Platform Interoperability", IEEE Software, 34(1), 2017, pp. 54-61.

[8] Brutti, A., A. Frascella, N. Gessa, P. de Sabbata, and C. Novelli, "Interoperability in the Smart City: A Semantic Approach for Merging Flexibility with Strictness", in 2018 IEEE International Conference on Smart Computing (SMARTCOMP). 2018.

[9] Brutti, A., P. de Sabbata, A. Frascella, N. Gessa, R. Ianniello, C. Novelli, S. Pizzuti, and G. Ponti, "Smart City Platform Specification: A Modular Approach to Achieve Interoperability in Smart Cities", in The Internet of Things for Smart Urban Ecosystems. 2019. Springer International Publishing.

[10] Chaturvedi, K. and T.H. Kolbe, "InterSensor Service: Establishing Interoperability over Heterogeneous Sensor Observations and Platforms for Smart Cities", in Proceedings of 2018 IEEE International Smart Cities Conference (ISC2). 2018.

[11] Chaturvedi, K. and T.H. Kolbe, "Towards Establishing Cross-Platform Interoperability for Sensors in Smart Cities", Sensors (Basel, Switzerland), 19(3), 2019.

[12] Cheng, B., S. Longo, F. Cirillo, M. Bauer, and E. Kovacs, "Building a Big Data Platform for Smart Cities: Experience and Lessons from Santander", in International Congress on Big Data. 2015.

[13] Cohen, S. and W. Money, "Establishing Smart City Technical Standards and Guidance", in Proceedings of the 26th International Conference on World Wide Web Companion - WWW '17 Companion. 2017.

[14] Danneels, L., S. Viaene, and J. van den Bergh, "Open data platforms: Discussing alternative knowledge epistemologies", Government Information Quarterly, 34(3), 2017, pp. 365-378.

[15] European Commission, European Interoperability Framework (EIF) for European public services, 2010.

[16] Faber, A., M. Riemhofer, S.-V. Rehm, and G. Bondel, "A Systematic Mapping Study on Business Ecosystem Types", in AMCIS 2019 Proceedings. 2019.

[17] Fahmideh, M. and D. Zowghi, "IoTSmart City Architectures an Analytical Evaluation", in Proceedings of 2018 IEEE 9th Annual Information Technology, Electronics and Mobile Communication Conference (IEMCON). 2018.

[18] Fahmideh, M. and D. Zowghi, "An Exploration of IoT Platform Development", Information Systems, 87, 2020.

[19] Ferguson, H., C. Vardeman, and J. Nabrzyski, "Linked data platform for building cloud-based smart applications 
and connecting API access points with data discovery techniques", in Proceedings of 2016 IEEE International Conference on Big Data (Big Data).

[20] Gläser, J. and G. \& Laudel, Experteninterviews und qualitative Inhaltsanalyse, 4th edn., VS Verlag, 2010.

[21] Hashem, I.A.T., V. Chang, N.B. Anuar, K. Adewole, I. Yaqoob, A. Gani, E. Ahmed, and H. Chiroma, "The role of big data in smart city", International Journal of Information Management, 36(5), 2016, pp. 748-758.

[22] Hernández, J.L., R. García, J. Schonowski, D. Atlan, G. Chanson, and T. Ruohomäki, "Interoperable Open Specifications Framework for the Implementation of Standardized Urban Platforms", Sensors (Basel, Switzerland), 20(8), 2020.

[23] Hwang, J., J. An, A. Aziz, J. Kim, S. Jeong, and J. Song, "Interworking Models of Smart City with Heterogeneous Internet of Things Standards", IEEE Communications Magazine, 57(6), 2019, pp. 74-79.

[24] Initiative Stadt.Land.Digitalc and Roland Berger $\mathrm{GmbH}$, Zukunft wird vor Ort gemacht: Digitalisierung und Intelligente Vernetzung deutscher Kommunen Ergebnisse einer repräsentativen Befragung von Kommunen im Auftrag des Bundesministeriums für Wirtschaft und Energie, 2018.

[25] International Organization for Standardization, "ISO/IEC 2382:2015 Information technology", Vocabulary Fundamental Terms, 2015.

[26] Janssen, M., R. Matheus, and A. Zuiderwijk, "Big and Open Linked Data (BOLD) to Create Smart Cities and Citizens: Insights from Smart Energy and Mobility Cases", in Electronic Government. 2015.

[27] Kazmi, A., M. Serrano, and J. Soldatos, "VITAL-OS: An Open Source IoT Operating System for Smart Cities", IEEE Communications Standards Magazine, 2(2), 2018, pp. 71-77.

[28] Kolbe, N., J. Robert, S. Kubler, and Y. Le Traon, "PROFICIENT - Productivity Tool for Semantic Interoperability inan Open IoT Ecosystem", in Proceedings of the 14th EAI International Conference on Mobile and Ubiquitous Systems: Computing, Networking and Services. 2017.

[29] Lewis, G.A., "The Role of Standards in CloudComputing Interoperability", Software Engineering Insitute, 2012.

[30] Lopes, F., S. Loss, A. Mendes, T. Batista, and R. Lea, "SoS-centric Middleware Services for Interoperability in Smart Cities Systems", in Proceedings of the 2nd International Workshop on Smart - SmartCities '16. 2016.

[31] Loutas, N., S. Goedertier, V. Peristeras, and S. Szekacs, "Building Cross-Border Public Services in Europe Through Sharing and Reuse of Interoperability Solutions", in Proceedings of the 14th European Conference on eGovernment: ECEG 2014. 2014.

[32] Maheshwari, D. and M. Janssen, "Reconceptualizing measuring, benchmarking for improving interoperability in smart ecosystems: The effect of ubiquitous data and crowdsourcing", Government Information Quarterly, 31, 2014, S84-S92.
[33] Myers, M.D., "Qualitative Research in Information Systems", MISQ Discovery, 21, 1997.

[34] Nickerson, R.C., U. Varshney, and J. Muntermann, "A method for taxonomy development and its application in information systems", European Journal of Information Systems, 22(3), 2013, pp. 336-359.

[35] Ojo, A., E. Curry, and F.A. Zeleti, "A Tale of Open Data Innovations in Five Smart Cities", in Proceedings of the 48th Hawaii International Conference on System Sciences. 2015.

[36] Peffers, K., T. Tuunanaen, M.A. Rothenberger, and S. Chatterjee, "A Design Science Research Methodology for Information Systems Research", Journal of Management Information Systems, 24(3), 2014, pp. 45-77.

[37] Petersen, K., R. Feldt, S. Mujtaba, and M. Mattsson, "Systematic Mapping Studies in Software Engineering", in Proceedings of the 12th International Conference on Evaluation and Assessment in Software Engineering. 2008.

[38] Soe, R.-M., "FINEST Twins platform for cross-border smart city solutions", in Proceedings of the 18th Annual International Conference on Digital Government Research. 2017.

[39] Sotres, P., J. Lanza, L. Sánchez, J.R. Santana, C. López, and L. Muñoz, "Breaking Vendors and City Locks through a Semantic-enabled Global Interoperable Internet-ofThings System: A Smart Parking Case", Sensors (Basel, Switzerland), 19(2), 2019.

[40] Tolcha, Y.k., H.M. Nguyen, J. Byun, K. Kwon, J. Han, W. Yoon, N. Lee, H. Kim, N. Pham, and D. Kim, "OliotOpenCity: Open Standard Interoperable Smart City Platform", in Proceedings of 2018 IEEE International Smart Cities Conference (ISC2). 2018.

[41] Välja, M. and T. Ladhe, "Towards Smart City Marketplace at the Example of Stockholm", in Proceedings of the 48th Hawaii International Conference on System Sciences. 2015.

[42] van der Klaauw, T., IoT Platforms for Cities: a Comparative Survey, 2019.

[43] Weking, J., M. Stöcker, M. Kowalkiewicz, M. Böhm, and $\mathrm{H}$. Krcmar, "Leveraging industry 4.0 - A business model pattern framework", International Journal of Production Economics, 225, 2020.

[44] Wirtz, B.W., W.M. Müller, and F. Schmidt, "Public Smart Service Provision in Smart Cities: A Case-StudyBased Approach", International Journal of Public Administration, 43(6), 2020, pp. 499-516.

[45] Zarko, I.P., S. Mueller, M. Plociennik, T. Rajtar, M. Jacoby, M. Pardi, G. Insolvibile, V. Glykantzis, A. Antonic, M. Kusek, and S. Soursos, "The symbIoTe Solution for Semantic and Syntactic Interoperability of Cloud-based IoT Platforms", in Proceedings of the 2019 Global Internet of Things Summit (GIoTS). 2019.

[46] Zhao, K. and M. Xia, "Forming Interoperability Through Interorganizational Systems Standards", Journal of Management Information Systems, 30(4), 2014, pp. 269-298. 